\title{
Clear-air turbulence in a changing climate
}

\author{
Paul D. Williams \\ Department of Meteorology, University of Reading, Reading, United Kingdom \\ (p.d.williams@ reading.ac.uk)
}

Atmospheric turbulence causes most weather-related aircraft incidents. Commercial aircraft encounter moderate-or-greater turbulence tens of thousands of times each year worldwide, injuring probably hundreds of passengers (occasionally fatally), costing airlines tens of millions of dollars and causing structural damage to planes. Clear-air turbulence is especially difficult to avoid, because it cannot be seen by pilots or detected by satellites or on-board radar. Clear-air turbulence is linked to wind shears within atmospheric jet streams, which are projected to be strengthened by anthropogenic climate change. However, the response of clear-air turbulence to projected climate change had not previously been studied.

We have shown using climate model simulations that clear-air turbulence changes significantly within the transatlantic flight corridor when the concentration of carbon dioxide in the atmosphere is doubled (Williams \& Joshi 2013). At cruise altitudes within $50-75^{\circ} \mathrm{N}$ and $10-60^{\circ} \mathrm{W}$ in winter, most clear-air turbulence measures show a $10-40 \%$ increase in the median strength of turbulence and a $40-170 \%$ increase in the frequency of occurrence of moderate-or-greater turbulence. Our results suggest that climate change will lead to bumpier transatlantic flights by the middle of this century.

An intensification of clear-air turbulence could have important consequences for aviation. Flight paths could become more convoluted, possibly lengthening journey times and increasing fuel consumption and emissions. Turbulence limits the lifetime of airframes and wings, which may require more frequent inspections. Aviation is partly responsible for changing the climate, but our findings show for the first time how climate change could affect aviation.

\section{Reference}

PD Williams \& MM Joshi (2013) Intensification of winter transatlantic aviation turbulence in response to climate change. Nature Climate Change 3(7), 644-648. DOI: $10.1038 /$ nclimate1866 


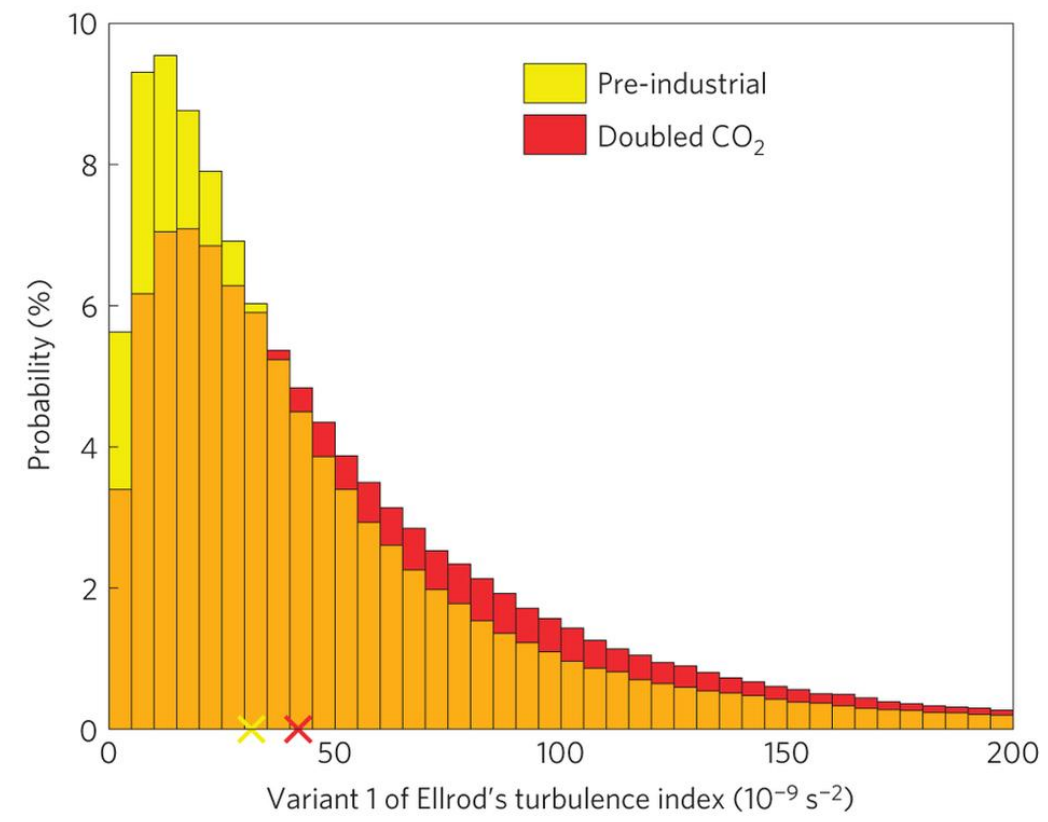

Fig. 1. Probability density functions of a clear-air turbulence diagnostic in winter at $200 \mathrm{hPa}$ within $50-75^{\circ} \mathrm{N}$ and $10-60^{\circ} \mathrm{W}$. Two histograms are over-plotted, from preindustrial and doubled- $\mathrm{CO}_{2}$ integrations. The overlap between the two distributions is shaded orange. The two crosses on the turbulence axis indicate the medians.

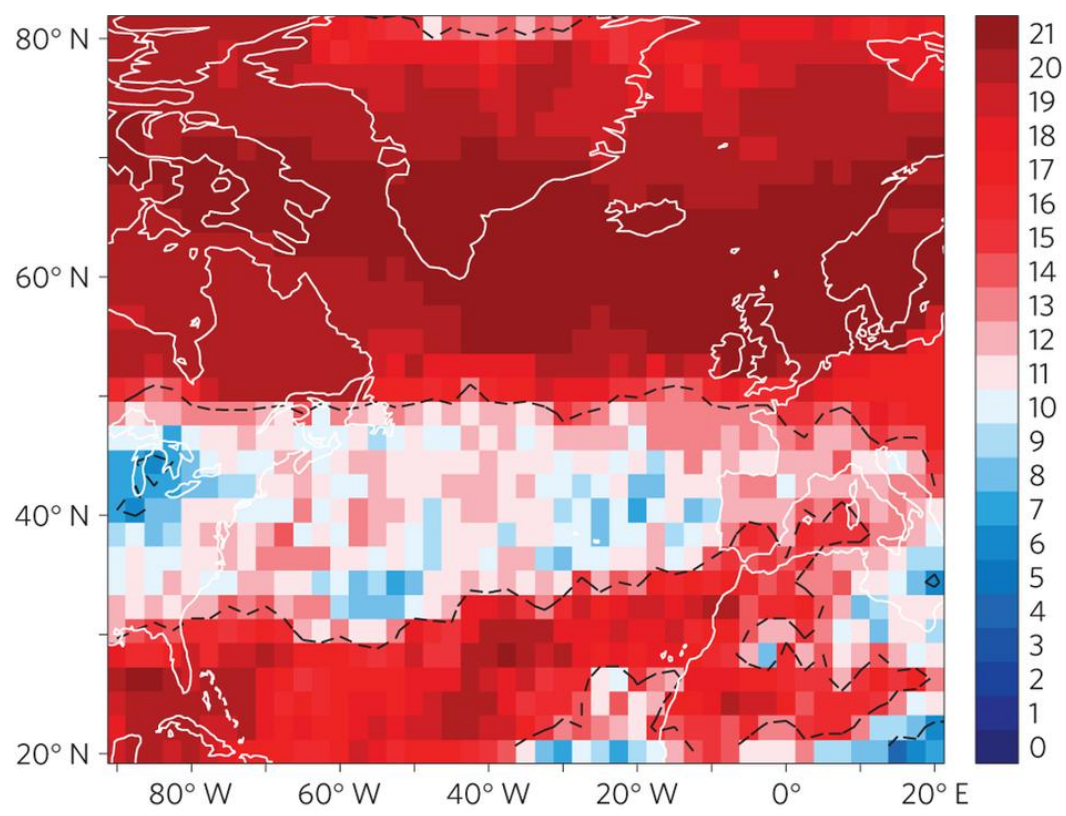

Fig. 2. Map showing how many of 21 clear-air turbulence diagnostics show an increase in the median in winter at $200 \mathrm{hPa}$, in the doubled- $\mathrm{CO}_{2}$ integration relative to the preindustrial integration. The black dashed lines indicate significance at the $90 \%$ level. 